\title{
Investigation of Pindan soil modified with polymer stablisers for road pavement
}

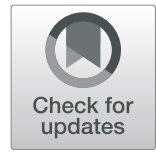

Hyun Kyu Park ${ }^{1 *}$, Hyuk Lee ${ }^{1}$ and Vanissorn Vimonsatit ${ }^{1,2}$

\begin{abstract}
Road failures are often caused by structural weaknesses, and particularly unsealed roads are vulnerable to water as water easily flows into road structures. Moisture susceptibility of materials is an important aspect when pavements are designed as moisture can weaken bonds between aggregates. Pindan soil is a red soil, known as a soft and moisture sensitive soil. Polymer stabilisers have been proved that they can improve soil mechanical properties by providing an internal waterproofing. Studies of the polymer-Pindan soil stabilisation have been focused on engineering performances, but literature shows little information on the fundamental information of Pindan soil. This project focuses on fundamental information of Pindan soil and its improved performances using polymer stabilisers. Plastic index, specific gravity and particle size distribution were tested to obtain the basic properties. Compaction, Unconfined Compressive Strength and California Bearing Ratio tests were performed to determine the mechanical properties. The chemical property was examined using X-ray diffraction. Furthermore, the waterproof effect of the polymers on the stabilised Pindan soil was investigated from capillary rise tests. In addition, the mechanical properties of individual soil grains were investigated using nanoindentation tests. The materials used for this investigation primarily consisted of Pindan soil collected in Broome, Western Australia, and three polymer products manufactured in Australia. Based on the results, it is evident that the failure behaviour, strain and strength as well as the basic properties of the soils are affected and changed by the Polymer stabilisers. The type of polymer influenced the optimum moisture contents and strengths rather than the amount of polymer. Similarly, Nanoindentation technology provided various information such as elastic modulus, hardness, packing density, stiffness, cohesion and fracture toughness of soils at nano-scales. Polymers can reduce water ingress and minimise moisture in the pavement structures. Thus, the structures can maintain its strength and prevent deformation, which will increase the lifetime of unsealed pavements.
\end{abstract}

Keywords: Stabilisation, Moisture, Silty, Soil, Stabiliser

\section{Introduction}

In Australia, about $60 \%$ of the road network is unsealed roads and requires high maintenance costs which are approximately 1 billion dollars per kilometre per year in the nation [1]. Typically, unsealed roads are made of natural materials or on-site soils. One of the main unsealed road materials in the Kimberley region of Western Australia is Pindan soil which is known as a soft and moisture-sensitive red soil [2-5]. Pindan soil is classified

\footnotetext{
* Correspondence: hyunkyu.park1@curtin.edu.au

${ }^{1}$ School of Civil Engineering and Mechanical Engineering, Curtin University, Kent Street, Perth, WA 6102, Australia

Full list of author information is available at the end of the article
}

as a silty sand or clayey sand, which is mainly sand but contains very small amount of silty or Clay [4]. Since Pindan soil is a potentially collapsible soil due to high void ratio, low density and low water content, it can be easily changed in volume on relatively high moisture contents and is very destructive to the pavement structure [4]. Therefore, if Pindan soil remains unsealed, there should be a requirement that any damage could be repaired by reworking and re-compaction. Pindan soil behaves like wet loose sand and has a low strength when it gets wet. However, the strength increases with high cohesion when the Pindan soil is "dried back" after compaction. Pindan soil has self-cementation ability due to 
the bridging effect of its minerals under dry moisture conditions, which can be used as the material of the pavement layers but it is a challenge to select the suitable Pindan soil for a pavement material due to its variability and difficulties in quality control. It is difficult to detect the suitability based on a visual inspection and simple laboratory tests to use Pindan soil as a pavement material [4].

Using the fundamental characteristics of Pindan soil, which can provide good strength when subjected to relatively dry conditions (i.e., moisture contents lower than its optimum moisture content), this could lead to a viable option on how to improve Pindan soil fundamentally. Pindan soil has self-cementation capabilities in a dry condition, and when Pindan soil can maintain its dry condition by not allowing them to be wetted, it can provide sufficient strength to use for construction purposes $[3,4,6]$. With the advancement in soil stabilising technology nowadays, a preferred drying condition of soils can be maintained by using stabilising agents such as a polymer, so-called, hydrophobic (water-repellence) properties [7]. Therefore, stabilisation of moisture-sensitive soils such as Pindan soils with polymers has been developed and expanded. Based on recent studies, polymers for soil stabilisation have a high resistance to water and excellent physical properties.

With the development of polymer technology in which waterproofing properties can be created, wetting problems of Pindan soil could be fundamentally resolved by using polymer stabilising binders as an internal waterproofing [7]. Since polymers act as a method of coating the aggregate with a polymer film, each ability of the polymers have an important effect on strength improvement and physical bonding [8]. However, most of the Polymer-Pindan soil stabilisation studies have been focused on engineering performances of the stabilised soil, so information on Pindan soil properties for road pavement is still limited. Correctly identifying Pindan soil properties, and the chemical and physical bonding mechanisms associated with polymer stabilisers are significantly important to improve the performance of Pindan soil and road conditions. The Pindan soil has been used as a pavement material in Western Australia, although limited information exists with Pindan soil properties for road pavement. Therefore, this study aims to explore an opportunity in stabilising Pindan soils with potential polymers in order to fundamentally prevent a wetting condition by creating a hydrophobic property through Pindan soils-polymer mixtures. If the problems of Pindan soils are identified and solved with polymers, it can be applied to other moisture-sensitive soils. This study examines the properties of Pindan soils to determine mechanical properties and evaluates the stabilisation to improve the performance of the Pindan soil using polymer stabilisers.

\section{Methodology}

The experiment consisted of producing a number of Pindan soils-polymer mixture batches with varying polymer contents and curing times. There are several important processes for sample testing; selection of suitable polymers, an appropriate amount of polymer and water, the mixing and curing process, and appropriate methods for testing of stabilised materials. The laboratory experiment consisted of producing a number of Pindan soil-polymer mixture batches with varying polymer contents and curing times. The materials used for this investigation primarily consisted of Pindan soil collected in Broome, Western Australia, and three polymer products manufactured in Australia. The QuantitativeXRD (QXRD) analysis for Pindan soil showed the following results as shown in Table 1 . The quantity is calculated only for materials with a crystal structure and not for amorphous materials.

The information of the polymers is provided by suppliers in Table 2. Polymer A consists of hydrated lime and cationic polymer. Polymer $\mathrm{B}$ and $\mathrm{C}$ are a polyacrylamide polymer and a styrene-acrylate copolymer. Polymer A and B have been used in the field since they are manufactured to use for soil stabilisations. Polymer C does not have a protocol for soil stabilisation as it is used for a raw material binder and has not been used as a soil stabiliser. The activity range zone of the polymer $\mathrm{C}$ was selected in comparison with the maximum dry density of Pindan soil of $18.74 \mathrm{kN} / \mathrm{m}^{3}$ [9].

The Pindan soil was treated by adding polymer A by weights of $1 \%, 2 \%$, and $3 \%$ of the soil. For polymer B and $\mathrm{C}$, solutions of a mixture of polymer and water were created in required polymer concentrations and then the soil was mixed with the solutions. Three different proportions of polymer $\mathrm{B}$ and $\mathrm{C}$ were added to the soil. The polymer B was added using ratio by weights of $0.001 \%$, $0.002 \%$ and $0.003 \%$ of the soil. The waterproofing effect of polymers is one of the important factors to improve the performance of the Broome-Pindan soil in wet conditions. Capillary rise test on the compacted soil is a simple method to assess the waterproofing effect of the polymers. Thereby, the Pindan soil was treated with polymers $\mathrm{A}, \mathrm{B}$ and $\mathrm{C}$ at the rate of $2 \%, 0.002 \%$ and $0.7 \%$ by weight, respectively. The samples were compacted to 98\% of the OMC using the modified proctor compaction method and cured for 16 days in a humidity cabinet in the temperature range of $21{ }^{\circ} \mathrm{C}$ to $25^{\circ} \mathrm{C}$ at $90 \%$ humidity.

Table 1 Quantitative XRD Analysis for Pindan Soil

\begin{tabular}{ll}
\hline Crystalline Mineral & $\%$ \\
\hline Quartz SiO2 & $95-96$ \\
Kaolinite Al4Si4O10(OH)8 & $4-5$ \\
\hline
\end{tabular}


Table 2 Polymer Information

\begin{tabular}{llll}
\hline & Polymer A & Polymer B & Polymer C \\
\hline Recommended Use & Soil stabiliser & Soil stabiliser & raw material binder \\
manufacturers' recommended dosage & $1.5 \%$ & $0.002 \%$ & $\mathrm{~N} / \mathrm{P}$ \\
Polymer Active Range & $1.0 \%-3.0 \%$ & $0.001 \%-0.003 \%$ & $0.5 \%-1.0 \%$ \\
Polymer Type & Cationic Polymer (with Hydrated Lime) & Anionic Polyacrylamides & Styrene - Acrylate Copolymer \\
Form & Powder & Powder & Powder \\
solubility in water & Insoluble & Miscible & dispersible \\
\hline
\end{tabular}

The compacted samples were placed in $10 \mathrm{~mm}$ deep of water at room temperature for $72 \mathrm{~h}$.

To obtain the mechanical properties of polymermodified Pindan soils, unconfined compression strength tests (UCS) and California bearing ratio (CBR) tests were performed using the modified compaction method based on Standards Australia [10-12]. In order to evaluate the mechanical behaviour and to determine the mechanical properties of individual soil grains, nanoindentation is considered one of the best techniques that can be used to obtain the mechanical properties of materials. The test came from the nanotechnology implementation in material science and engineering to evaluate physical properties on a small scale. Indentation testing is performed essentially by touching the material whose mechanical properties are not known, such as hardness and elastic modulus, by using other materials whose properties are known [13]. The nanoindentation instrument is recently accepted as a standard test process for the characterisation of the physical properties of materials [14]. An advantage of the indentation test is that the material can be characterised based on the indentation load and depth of the material during loading and unloading.

Nanoindentation test results are a feasibility study of soil fundamental mechanical properties such as porosity distribution, and energy transferred fracture toughness. Also, the indentation method is commonly used in engineering applications recently to obtain a deep understanding of soil properties [14-16]. It is difficult to determine the soil mechanical properties with soil particles using conventional tests due to the particle size and the lack of fine-scale analysis methods [14, 17]. The conventional testing methods provide a bulk density of the soil, whereas the nanoindentation as presented in this study provides grain properties that are not affected by the test configuration and compaction efforts. Moreover, the nanoindentation approach enables a quantitative assessment of the porosity in the material. The composition of the soil is not only related to the roughness and surface variability of the soil, but also to the stiffness and adhesion properties [16]. The chemical composition of soil also affects the binding mechanism of soil [18]. In addition, soil activity at the field-scale is potentially affected by major chemical reactions that appear in the soil at the nano-scale [16]. Therefore, more nanoindentation study needs to be conducted and linked to the conventional testing methods to find the application in soil mechanics.

Nanoindentation tests using Berkovich indenter tip was conducted on individual Pindan red soils from Broom, Kimberley Region of Western Australia. A sample of soil was cast with an epoxy matrix then was ground and polished to reduce the surface roughness [19]. For the measurement of hardness and elastic modulus of soil grain, nanoindentation test was carried out with XP system with Poisson's ratio of 0.25 was assumed [20]. An application of the nanoindentation technique was successfully made for the microporomechanics of Pindan soil, and a comprehensive variation behaviour in the Pindan soil was observed. A number of researchers $[2,4,6]$ have written about the behaviour of Pindan soils when their moisture contents rise, and there have been several conflicting results.

\section{Results and discussion Soil properties}

Soil classification systems generally group soils with similar properties into relatively broad categories because soils have a variety of characteristics and behaviours. Seven Pindan soil samples collected locally in two sites of Broome; Gantheaume Point Rd. (G.P) and Cape Leveque (C.L) were used for the index and classification tests based on AS and ASTM Standards [21-24] as shown in Table 3.

The CBR values for the unsoaked and soaked samples and the swelling percentage of the soaked samples were tested. The relative compaction was to be $95 \%$ to $98 \%$ of maximum dry density for all CBR tests. The CBR tests on the unsoaked Pindan soil samples result in the range of CBR 11.01-12.72\% for G.P. samples and CBR 11.82$12.74 \%$ for C.L samples, and on soaked samples result in CBR 10.35-10.98\% for G.P. samples and CBR 10.86$11.29 \%$ for C.L samples. The swelling percentage of unsoaked samples results in the range of $0.06-0.11 \%$ for C.L samples and $0-0.15 \%$ for C.L samples. In addition, based on the standard proctor compaction test, the values for the optimum moisture content (OMC) and maximum dry density (MDD) of the Pindan soil samples 
Table 3 Index and Classification of Broome-Pindan Soil

\begin{tabular}{|c|c|c|c|c|c|c|c|}
\hline \multirow{2}{*}{$\begin{array}{l}\text { Collected location } \\
\text { Properties }\end{array}$} & \multicolumn{2}{|c|}{ Gantheaume Point Rd. (G.P) } & \multicolumn{5}{|c|}{ Cape Leveque (C.L) } \\
\hline & Raw Material & $\begin{array}{l}\text { Road Surface } \\
\text { Material }\end{array}$ & $\begin{array}{l}\text { Road Shoulder } \\
\text { Material }\end{array}$ & Raw Material & $\begin{array}{l}\text { Road Surface } \\
\text { Site } 1\end{array}$ & $\begin{array}{l}\text { Road Surface } \\
\text { Site } 2\end{array}$ & $\begin{array}{l}\text { Road Shoulder } \\
\text { Site } 2\end{array}$ \\
\hline Gravel \% & 9.31 & 2.55 & 0.01 & 0.16 & 2.11 & 0.02 & 0.01 \\
\hline Sand \% & 86.65 & 93.99 & 96.7 & 93.81 & 96.36 & 98.03 & 94.29 \\
\hline Silt \% & 4.04 & 3.46 & 3.29 & 6.03 & 1.53 & 1.95 & 5.70 \\
\hline Specific Gravity (Gs) & 2.60 & 2.60 & 2.57 & 2.61 & 2.59 & 2.59 & 2.58 \\
\hline Plasticity Index (PI) & \multicolumn{7}{|l|}{ Non-Plastic } \\
\hline Soil Classification & \multicolumn{7}{|l|}{ Silty Sand (SM) } \\
\hline
\end{tabular}

lie between 9.8 to $10.8 \%$ and 17.6 to $18.1 \mathrm{kN} / \mathrm{m}^{3}$, respectively. They displayed similar OMC and MDD results and showed no signification change with increasing moisture content in the compaction test. The seven Pindan soil samples belong to the same classification category and, show the similar values of the basic mechanical properties.

The information on the Pindan soils used in the nanoindentation tests is shown in Table 4. According to the deconvolution technique from the literature [20], the elastic modulus and hardness values for Pindan soil were observed as $68.1 \pm 12.7 \mathrm{GPa}$ and $10.6 \pm 0.9 \mathrm{GPa}$, respectively, as presented in Fig. 1. The elastic modulus of Pindan soil, however, is lower than the elastic modulus of quartz, which has an elastic modulus of around $124 \mathrm{GPa}$ based on an indentation test.

Similarly, the stiffness and hardness-packing density scaling were tested on Pindan soil [20]. The results of soil particle properties show that stiffness and cohesion were $92.7 \mathrm{GPa}, 4.1 \mathrm{GPa}$, respectively. The packing density of the sample was determined as $0.863 \pm 0.032$, as shown in Fig. 2. From the results of the packing density distribution, Pindan soil yields total porosity $\xi=0.137$. This way of determining the porosity using a statistical technique provides a new non-invasive approach which, otherwise, would be difficult to estimate the porosity of ground materials using a classical method [25]. The indentation fracture toughness was also investigated, the median value of the fracture toughness of Pindan soil was obtained as $3.7 \pm 0.5 \mathrm{MPa} \mathrm{m}^{1 / 2}$ as shown in Fig. 3 . The results of energy transferred fracture toughness of Pindan soil was obtained as $3.1 \pm 0.8 \mathrm{MPa} \mathrm{m}^{1 / 2}$. The approach of using energy transferred fracture toughness was able to extract the fracture toughness of indentation test results.

\section{Characteristics of soil with polymer contents Moisture susceptibility}

Figure 4 presents the capillary rise (CR) results as a percentage of the specimen height. The samples A, B and C are the compacted mixtures with Polymer A, B and C, respectively. Polymer A decreased capillary rise rate and reduced moisture sensitivity significantly. When sample B was placed in water, it seemed to have some water effect on the surface, such as a slight collapse, but after that, the surface of sample B was no longer affected by water. The untreated sample and sample $\mathrm{C}$ were risen the water similarly and fully saturated after around $2.5 \mathrm{~h}$ from the start. The untreated sample was completely collapsed after the fully saturated point. All treated samples remained unchanged and seemed to maintain some strength as well as shape. Swelling (S) does not appear on the treated samples after immersion, and the untreated sample could not be measured as the sample shape was collapsed after saturated.

It has been found that the polymer could provide sufficient water-resistance to the soil during long-term exposure to water. From the results, it clearly shows the capillary rise rate of samples $B$ and $C$ was higher than the untreated sample and the sample A, as shown in Fig. 4. Polymers B and C filled the void spaces and thereby reduced the void size of the treated samples. Therefore, since the size of the voids became thinner, and the rate of the capillary rise was increased.

On the other hand, the capillary rise did not occur very much, and it went down to the original water position again for sample A. Sample A almost did not change at all and maintained the sample in a dry condition. Lacey [7] explained that polymer A reacts with water and soils to create a hydrophobic soil matrix between the soil particles, limiting water penetration. It could be because the hydrated lime, $\mathrm{Ca}(\mathrm{OH})_{2}$ was reacted with pozzolan in water. The pozzolan is deploymerised

Table 4 Properties of Pindan soil grain used in Nanoindentation

\begin{tabular}{lllllll}
\hline \multicolumn{1}{l}{ Pindan Sample } & & & & \\
\hline & Sample collected Location & Soil Condition & Specific Gravity (Gs) & Plasticity Index (PI) & Classification & Collapsibility \\
\hline Property & Cape Leveque (C.L) & Raw Material (Sand) & 2.61 & Non-Plastic & Silty Sand (SM) & Slightly collapsible \\
\hline
\end{tabular}



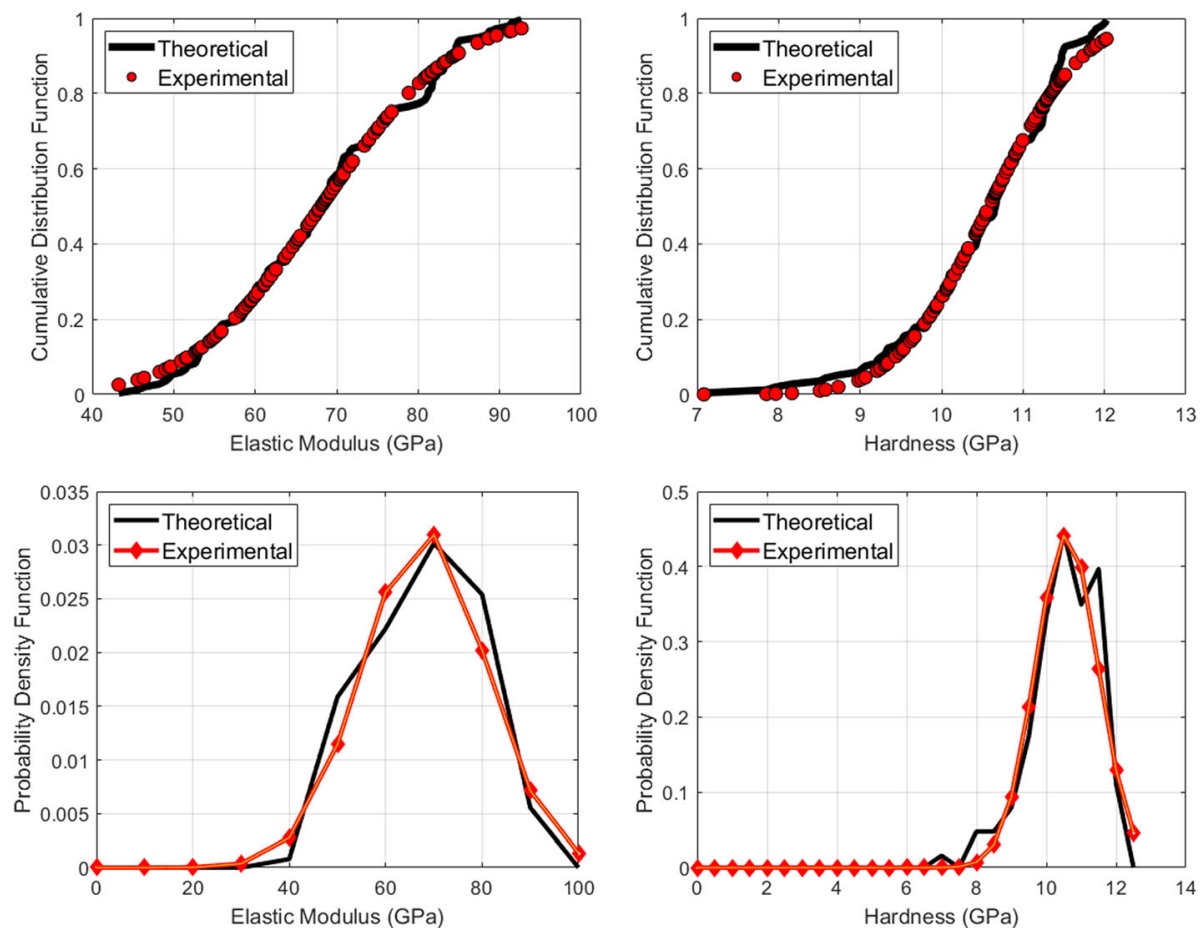

Fig. 1 Statistical Indentation Analysis; Top - cumulative distribution functions (CDF), Bottom - probability density function of elastic modulus (left) and hardness (right)

into $\mathrm{Ca}^{2+}, \mathrm{K}^{+}$and $\mathrm{Na}^{+}$, and the pozzolanic reaction occurs between free calcium $\left(\mathrm{Ca}^{2+}\right)$ and dissolved silica and alumina. When the reaction happens at a High $\mathrm{pH}$ value of around 12.5 at $20^{\circ} \mathrm{C}$ under $\mathrm{OH}^{-}$, it turns into gel formation in amorphous form and thereby, the voids filled up by the cementitious material [26]. As the void space between the soil particles is filled by the cementitious material, sample A was not saturated with water.

\section{Modified compaction}

A series of performance tests; Modified compaction tests, Unconfined compression strength tests, and California bearing ratio tests were performed to evaluate and compare material properties and characteristics with respect to polymer contents and curing times. Soil compaction is the process of increasing soil density by reducing the space between soil particles by applying forces. The reduction of pore space is accompanied by an increase in soil density, and in laboratory conditions, an increase in soil density is generally seen as an increase in soil strength due to adding more soil. Fig. 5 illustrates the compaction curves within the same scale to compare the untreated and treated samples. Table 5 provides the optimum moisture contents (OMC) and maximum dry density (MDD) values obtained from the moisturedensity relationship curve of the compacted samples. As
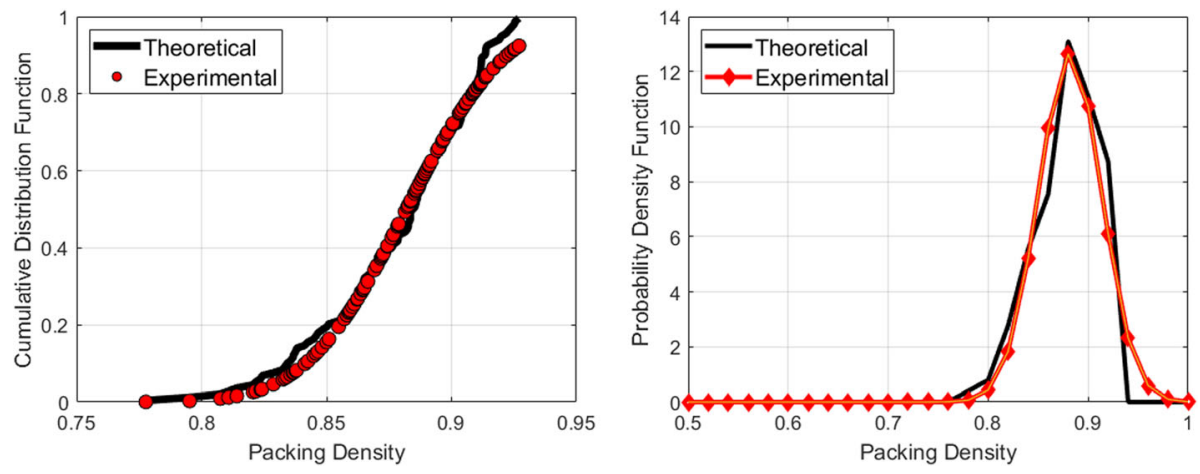

Fig. 2 Statistical Indentation Analysis; left - cumulative distribution functions (CDF), right - probability density function of packing density 


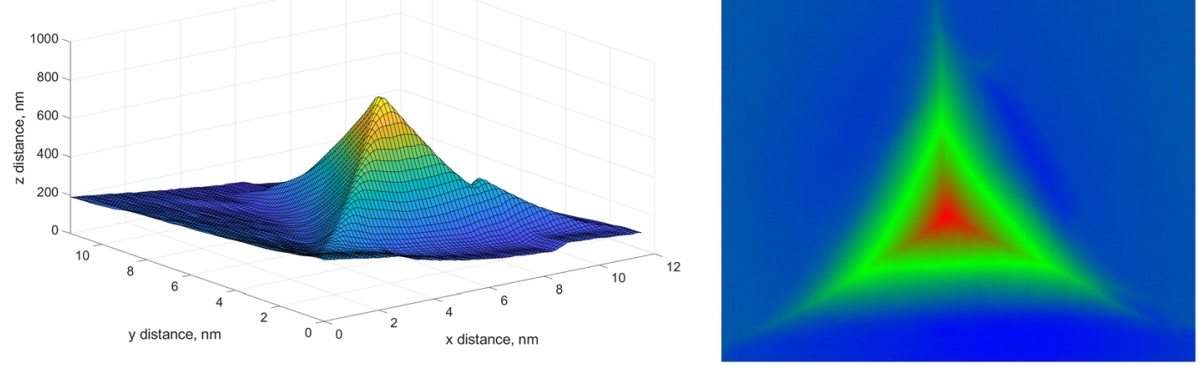

Fig. 3 Investigation of fracture toughness inverted 3D image (left) and residual impression (right)

can be seen in Fig. 5, the effect of adding the polymers on the moisture-density relationship for the Pindan soil can be assessed through the compaction test results.

Comparing the OMC and MDD between the untreated sample and all mixtures, all polymers reduced OMC and increased MDD values. The mixture can reduce the required water content to achieve the MDD, which is desirable for the construction of the Kimberley region. However, the dry unit weight was getting rapidly reduced after each $\mathrm{OMC}$ and the dry density decreased to or below the dry unit weight of the untreated sample. Each of the polymers maintained a graph of the same pattern at different doses. The increase in density is probably because the polymers filled the pore space and reduced the porosity of the treated samples. The untreated Pindan soil recorded a maximum dry unit weight at a moisture content of $9.4 \%$. When the moisture content is below $9.4 \%$, the compaction is interrupted because of the high friction between the soil particles and the moisture content interferes with the compaction due to the high pore water pressure after $9.4 \%$.

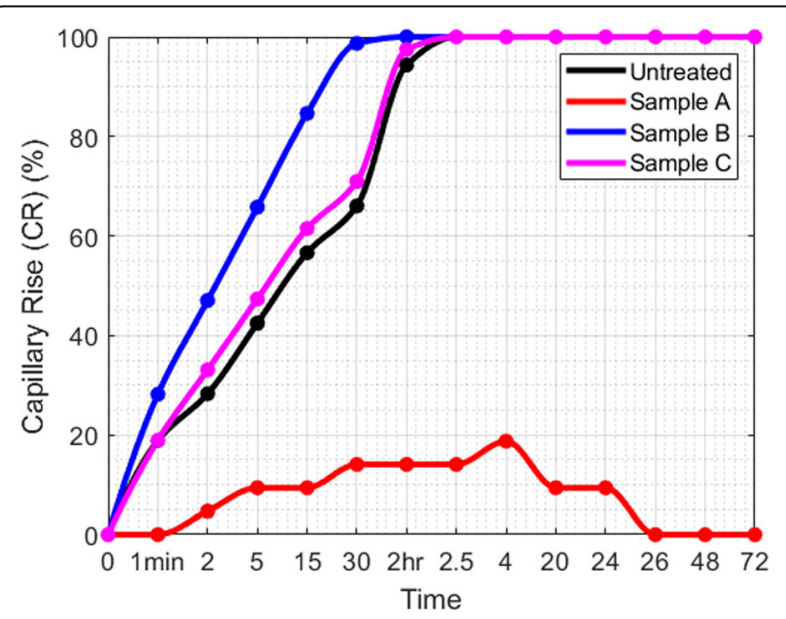

Fig. 4 Capillary Rise of Compacted Samples
From the results, it clearly shows that there was an increase in MDD for the treated samples compared to the untreated samples up to the optimum moisture content. The results may be because the polymers filled the pore space and reduced the porosity of the treated samples until it reached the optimum moisture content. However, there was a decrease in MDD for the treated samples after the OMC, which was equal or more reduced than the untreated samples decreased. After the OMC, the reaction of water and polymer occurs, but the polymer might leak out with the water during or after the compaction process. Another reason is that after the polymers fill the void spaces between the soil particles, these materials, which have smaller densities than the density of the soil, could replace the small particles of the sand to reduce the density rapidly.

\section{Unconfined compressive strength}

UCS testing was performed on untreated and treated samples at two different curing times of $1 \mathrm{~h}$ and 16 days. Testing of samples at 1-h curing was to assess when the road opens to the public immediately after road construction or repair. Testing at 16 days curing was to

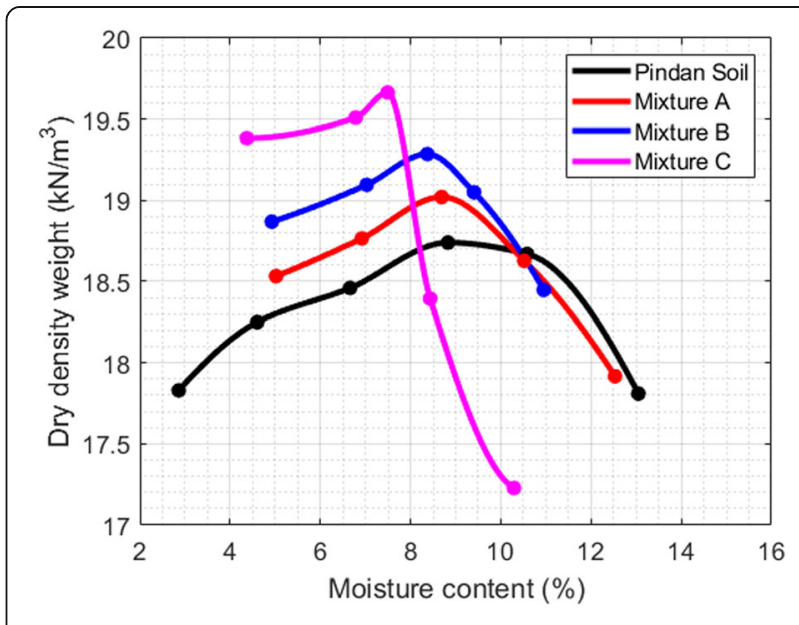

Fig. 5 Comparison of the untreated sample and the treated samples 
Table 5 Optimum Moisture Contents (OMC) and Maximum Dry Density (MDD) of Broome-Pindan Soil and Mixtures

\begin{tabular}{lll}
\hline Modified Proctor Compaction Test & & \\
\hline Sample & OMC (\%) & MDD $\left(\mathrm{kN} / \mathrm{m}^{3}\right)$ \\
\hline Untreated Pindan Soil & 9.4 & 18.74 \\
Sample A (1\% Polymer) & 8.6 & 19.05 \\
Sample A (2\% Polymer) & 8.2 & 18.80 \\
Sample A (3\% Polymer) & 8.2 & 18.90 \\
Sample B (0.001\% Polymer) & 8.3 & 19.21 \\
Sample B (0.002\% Polymer) & 8.2 & 19.15 \\
Sample B (0.003\% Polymer) & 8.0 & 19.19 \\
Sample C (0.5\% Polymer) & 7.4 & 19.70 \\
Sample C (0.7\% Polymer) & 7.2 & 19.40 \\
Sample C (1.0\% Polymer) & 7.2 & 19.42
\end{tabular}

assess the change in strength over time after road stabilisation. The effect of using three different polymers on the compressive strength of the untreated and treated samples under unconfined conditions was assessed using the UCS testing. For 16 day curing samples, the samples were compacted to $98 \%$ of the MDD using the modified proctor compaction method and cured for 16 days in a humidity cabinet after extrusion. The temperature of the cabinet remained in the range of $21^{\circ} \mathrm{C}$ to $25^{\circ} \mathrm{C}$ at $90 \%$ humidity for 16 days. The samples were selected using the standard deviation with a $90 \%$ confidence level. Typical graphs of UCS for $1 \mathrm{~h}$ and 16 days cured samples are presented in Fig. 6, respectively, and the average of UCS data is presented in Table 6 for each sample.

In $1 \mathrm{~h}$ curing condition, the average UCS value of untreated soil samples was $34.7 \mathrm{kPa}$ and all treated samples showed better UCS values ranging from 37.7 to $49.1 \mathrm{kPa}$. With the 16 days curing, the UCS value of $1021 \mathrm{kPa}$ for the samples with no stabiliser was obtained and the highest UCS value of $1948 \mathrm{kPa}$ was from samples treated with polymer $\mathrm{C}$. According to the result of the $1 \mathrm{~h}$ cured samples, the polymers increased the compressive strength and the percentage of the strain at peak loads compared to the untreated samples. Based on the result of the 16 days cured samples, polymer $C$ increased the compressive strength as compared to the untreated sample, but polymers A and B caused a decrease in strength and strain.

Polymer A influenced the colour of the sample and showed micro-cracks on the surface of the sample during curing. Thus, the results of both stress and strain were reduced. The micro-cracks could be just due to shrinkage cracking or due to carbonation of the hydrated lime or could be the corrosion due to iron-hydroxide (i.e. $\left.\mathrm{Fe}(\mathrm{OH})_{2}\right)$. Polymer B had no significant effect on the strength of the 16 days cured samples while had a significant effect on the strength of the 1-h cured samples, and polymer $\mathrm{C}$ significantly increased strength as compared to the 16 days cured untreated samples and other polymer samples. Polymer B caused a blow at the point of failure, which seems to occur when the bonding was broken together. Polymer B changed the properties of the soil from ductile behaviour to brittle behaviour, as shown in Fig. 6b. When polymers $\mathrm{A}$ and $\mathrm{C}$ were observed on the curves of the 16 days cured samples, the curves appeared to fall slightly more slowly in strength after the ultimate tensile strengths, while the untreated sample sharply decreased. It seems to be due to the polymer holding between the soil particles.

\section{California bearing ratio}

The CBR test is generally used to evaluate the subgrade strength of roads, and its value can be used to determine the thickness of pavement layers. The unsealed pavement design should use the lowest CBR values, mostly from soaked samples. The results of the CBR test for unsoaked and soaked conditions are presented in Table 7, and the typical UCS graphs for samples with and without polymer stabilisers in unsoaked and soaked conditions are presented in Fig. 7, respectively. In the CBR test, when mixing

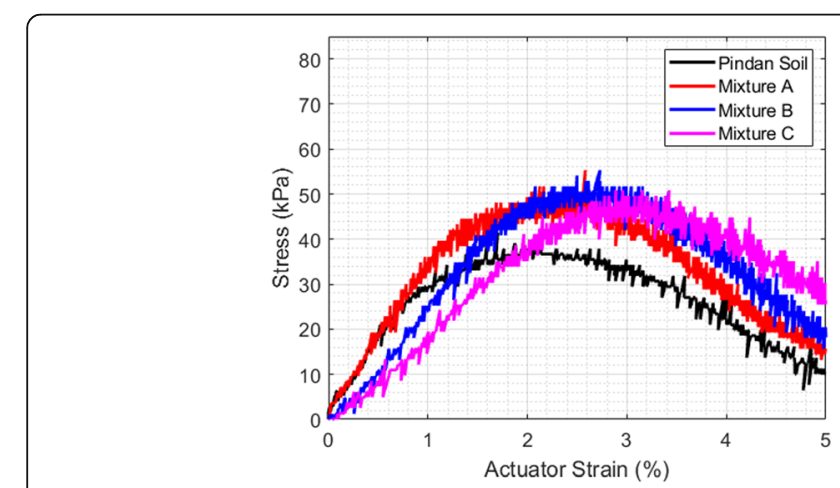

(a)

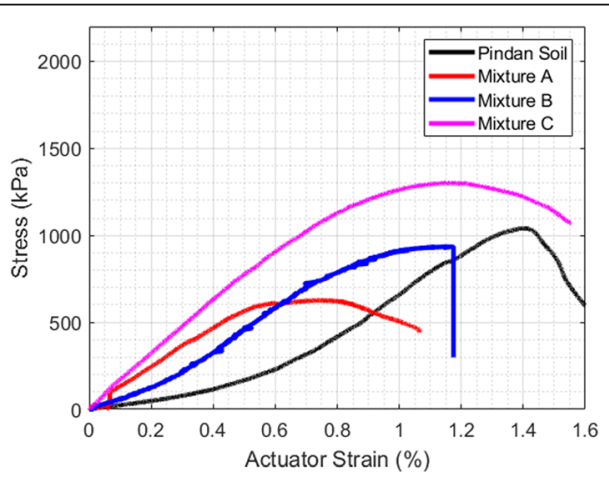

(b)

Fig. 6 Typical Unconfined Compressive Strength Curves of the compacted samples. a 1-h cured samples, b 16 days cured samples 
Table 6 Averages of UCS Results for the 1-h and 16 days cured samples

\begin{tabular}{|c|c|c|c|c|}
\hline \multirow[b]{2}{*}{ Sample } & \multicolumn{2}{|c|}{ UCS of 1-h Curing Samples } & \multicolumn{2}{|c|}{ UCS of 16 days Curing Samples } \\
\hline & $\begin{array}{l}\text { Actuator strain at } \\
\text { peak load }(\%)\end{array}$ & $\begin{array}{l}\text { Peak compressive } \\
\text { strength }(\mathrm{kPa})\end{array}$ & $\begin{array}{l}\text { Actuator strain at } \\
\text { peak load (\%) }\end{array}$ & $\begin{array}{l}\text { Peak compressive } \\
\text { strength }(\mathrm{kPa})\end{array}$ \\
\hline Pindan Soil & 2.25 & 34.67 & 1.398 & 1041 \\
\hline Sample A (1\%) & 2.28 & 37.67 & 0.83 & 603 \\
\hline Sample A (2\%) & 2.78 & 38.5 & 0.83 & 762 \\
\hline Sample A (3\%) & 3.15 & 39.17 & 0.88 & 628 \\
\hline Sample B (0.001\%) & 2.53 & 48.5 & 0.89 & 895 \\
\hline Sample B (0.002\%) & 2.43 & 48.8 & 1.28 & 949 \\
\hline Sample B (0.003\%) & 2.48 & 49.1 & 1.02 & 979 \\
\hline Sample C (0.5\%) & 2.55 & 38.5 & 1.10 & 1313 \\
\hline Sample C (0.7\%) & 2.93 & 43.8 & 1.37 & 1648 \\
\hline Sample C (1.0\%) & 3.20 & 44.4 & 1.34 & 1948 \\
\hline
\end{tabular}

the polymer $\mathrm{C}$ with Pindan soil, the moisture content should not exceed the optimum moisture content. When the amount of water greater than the optimum moisture content was added, the density of the compacted sample dropped remarkably. In relation to this, the CBR values of the samples also dropped significantly up to a CBR of 4 regardless of the amount of the polymer. The average CBR value of the untreated soil samples was measured to be around 19. Most of the treated samples in both unsoaked and soaked conditions provided similar or higher CBR values than the untreated samples. The unsoaked and soaked samples did not show any significantly different results.

In the CBR test, sample A showed the highest CBR values of 30.13 and 26.18, respectively, in unsoaked and soaked conditions. Moreover, polymer $\mathrm{C}$ showed the lowest CBR values in both unsoaked and soaked conditions. The $1 \%$ content of the polymer A did not affect the CBR value, which may increase over time, as shown in the UCS results. The reaction of the polymer might not be started and the reaction would gradually take place over time, which also applies to all polymers. The polymers might need more time to react to increase the CBR value. Polymer A showed higher CBR value as the amount of polymer increased, whereas the CBR value decreased as the polymer amount of polymer $\mathrm{C}$ increased. For polymer B, it had the highest CBR values when the polymer ratio was $0.002 \%$ in both unsoaked and soaked conditions.

In general, the unsealed pavement design should use the lowest CBR values, mostly from soaked samples. According to Austroads Unsealed Pavements Design [27], unsealed roads using Pindan soil should be stabilised and must have a minimum compacted surfacing thickness of $100 \mathrm{~mm}$. For subgrade layers, the minimum thickness for unsealed road construction is $150 \mathrm{~mm}$ based on the CBR results. Road failures are often caused by structural weaknesses, and particularly unsealed roads

Table 7 Averages of the CBR values for saturated and unsaturated samples

\begin{tabular}{lll}
\hline Sample & CBR (\%) & \\
\cline { 2 - 3 } & Unsoaked Condition Sample & Soaked Condition Sample \\
\hline Pindan Soil & 19.05 & 19.08 \\
Sample A (1\%) & 18.64 & 18.91 \\
Sample A (2\%) & 22.87 & 20.20 \\
Sample A (3\%) & 30.13 & 26.18 \\
Sample B (0.001\%) & 24.39 & 18.35 \\
Sample B (0.002\%) & 25.03 & 25.25 \\
Sample B (0.003\%) & 23.31 & 24.24 \\
Sample C (0.5\%) & 23.88 & 19.53 \\
Sample C (0.7\%) & 20.11 & 18.35 \\
Sample C (1.0\%) & 11.11 & 9.68 \\
\hline
\end{tabular}




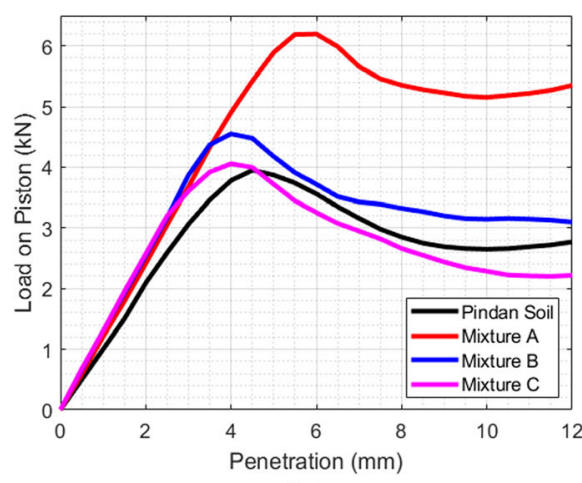

(a)

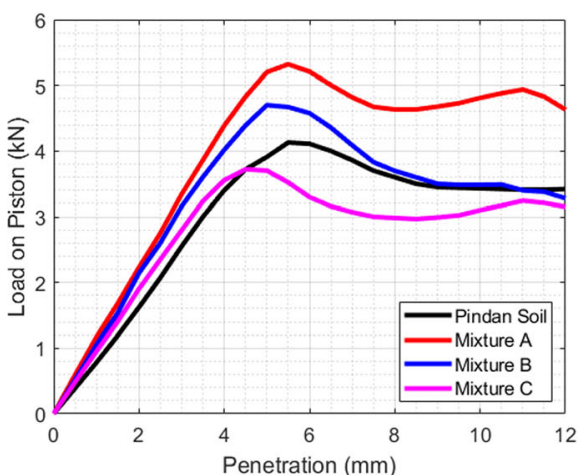

(b)

Fig. 7 Typical CBR (a) Unsoaked Condition, (b) Soaked Condition

are vulnerable to water as water easily flows into road structures. Polymer A reduces water ingress into the subgrade and minimises moisture in the base-course. Therefore, a stabilised base-course maintains its strength and prevents the deformation of subgrade structures, which increases the lifetime of unsealed pavements. Polymer B also has economic benefits in road design by stabilising the soil and increasing its strengths.

\section{Conclusion}

This paper presented the fundamental properties of Pindan soils and stabilisation to improve its performance using polymer stabilisers. Pindan soils were tested according to classification categories based on basic physical characteristics such as index properties and particle size distribution, and they were classified as silty sand (SM) and the plasticity index was non-plastic. The Pindan soils also showed similar mechanical property values according to the compaction and CBR tests. Similarly, nanoindentation technology provided various information such as elastic modulus, hardness, packing density, stiffness, cohesion and fracture toughness of soils at nano-scales. In addition, in UCS test, when compared to the performance of soil with no stabilisers in 1 hour curing condition, it appears that all treated samples provide higher strength and strain. Based on Compaction and CBR test results, all the tested Pindan samples did not exhibit any moisture-sensitivity behaviour, thereby the Broome-Pindan soil can be used as a road material for the base, subbase and subgrade pavement structures in both dry and wet conditions. The capillary rise test proved that polymer stabilisers have a high resistance to water and can play the role of waterproofing. Each of the polymers showed different mechanical properties and material failure modes. It is recommended that polymer $\mathrm{C}$ is not to be used as a road stabiliser because the bonding is weak to water and significantly reduces the CBR values. Polymer A, on the other hand, is resistant to water and reduces water ingress, thus stabilising the pavement structures to maintain strength, increasing the life of the unsealed pavement. Polymer B also stabilises the soil well and increases its strength even when the amount of polymer is changed.

\section{Abbreviations \\ $\xi$ : Porosity; CBR: California Bearing Ratio; CDF: Cumulative Distribution Functions; CL: Cape Leveque; CR: Capillary Rise; Gs: Specific Gravity; \\ GP: Gantheaume Point; MDD: Maximum Dry Density; OMC: Optimum Moisture Contents; PI: Plasticity Index; QXRD: Quantitative X-Ray Diffraction; S: Swelling; UCS: Unconfined Compression Strength; XRD: X-Ray Diffraction}

\section{Acknowledgments}

The authors would like to acknowledge the assistance of Dr. Peerapong Jitsangiam, Department of Civil Engineering, Chiang Mai University in

Thailand. The authors also would like to express appreciation to Dr. Korakod Nusit, Department of Civil Engineering, Naresuan University in Thailand. The authors are very grateful to all the technicians of the School of Civil and Mechanical Engineering, Curtin University in WA, Australia.

\section{Authors' contributions}

Hyun Kyu Park conceived of the presented idea and provided conceptual for all aspects of the project. Hyun Kyu Park and Hyuk Lee performed the computation and developed the theory. Hyuk Lee verified the analytical methods. Hyuk Lee and Vanissorn Vimonsatit suggested and commented on the data. Vanissorn Vimonsatit supervised Hyun Kyu Park in the investigation of this study. All authors discussed the results and contributed to the final manuscript. The authors read and approved the final manuscript.

\section{Funding}

The authors declare non-finical competing interests.

\section{Availability of data and materials}

Not applicable.

\section{Competing interests}

The authors declare no competing interests.

\section{Author details}

${ }^{1}$ School of Civil Engineering and Mechanical Engineering, Curtin University, Kent Street, Perth, WA 6102, Australia. ${ }^{2}$ School of Engineering, Macquarie University, Sydney, NSW, Australia. 


\section{References}

1. Sharp K, Andrews B (2009) Stabilising unsealed Roads efficiently. Road Transp Res 18(3):69

2. Kenneally KF, Edinger DC, Willing T (1996) Broome and beyond: plants and people of the Dampier Peninsula, Kimberley, Western Australia. Department of Conservation and Land Management vi, 256p.-col. illus. ISBN $073096972 X$ En Plant records. Geog, Como, p 7

3. Main Roads, W.A., A guide to the selection and use of naturally occurring materials as base and subbase in roads in Western Australia. 2008, Report

4. Emery S, Masterson S, Caplehorn M (2003) Sand-Clay pindan material in pavements as a structural layer. In: Proc. 21st Australian Road Research Board Conference

5. Smith J, Sullivan $L$ (2014) Construction and maintenance of embankments using highly erodible soils in the Pilbara, North-Western Australia. Int J GEOMATE 6(2):897-902

6. Sinclair Knight Merz (2010) Broome north development Engineering report final. LandCorp. Rev 5.

7. Lacey G (2004) Do dry powdered polymers work. In: Proceedings from stabilisation of road pavements seminar. NZ Highway Institute of Technology, Auckland

8. Welling GE (2012) Engineering performance of polymer amended soils. California Polytechnic State University, San Luis Obispo

9. Park HK (2018) Characterisation and Performance of Pindan Soils Modified with Polymer Stabilisers (Doctoral dissertation, Curtin University).

10. Standards Australia, Determination of the California Bearing Ratio of a soil Standard laboratory method for a remoulded specimen (AS 1289.6.1.1). Retrieved from Standards Online. 2014

11. Standards Australia, Unconfined compressive strength of compacted materials (AS 5101.4:2008). Retrieved from Standards Online. 2008

12. Standards Australia, Soil compaction and density tests - Determination of the dry density/moisture content relation of a soil using modified compactive (AS 1289.5.2.1:2017). Retrieved from Standards Online. 2017

13. Fischer-Cripps AC (2011) In: SpringerLink (ed) Nanoindentation. Springer New York, New York

14. Daphalapurkar N et al (2011) Determination of mechanical properties of sand grains by nanoindentation. Exp Mech 51(5):719-728

15. Xian S et al (2019) Investigation of mechanical properties of bedded shale by nanoindentation tests: a case study on lower Silurian Longmaxi formation of Youyang area in Southeast Chongqing, China. 石油勘探与开 发 46(1):163-172

16. Gazze $S$ et al (2018) Organic matter identifies the nano-mechanical properties of native soil aggregates. Nanoscale 10(2):520-525

17. Lehmann J et al (2008) Spatial complexity of soil organic matter forms at nanometre scales. Nat Geosci 1(4):238-242

18. Solomon D et al (2012) Micro-and nano-environments of carbon sequestration: multi-element STXM-NEXAFS spectromicroscopy assessment of microbial carbon and mineral associations. Chem Geol 329:53-73

19. Bobko C, Ulm F-J (2008) The nano-mechanical morphology of shale. Mech Mater 40(4):318-337

20. Lee H, Vimonsatit V, Chindaprasirt P (2016) Mechanical and micromechanical properties of alkali activated fly-ash cement based on nano-indentation. Constr Build Mater 107:95-102

21. Standards Australia, Soil classification tests - Determination of the soil particle density of a soil (AS 1289.3.5.1-2006). Retrieved from Standards Online. 2006

22. Standards Australia, Soil classification tests - Determination of the particle size distribution of a soil - Standard method of analysis by sieving (AS 1289. 3.6.1). Retrieved from Standards Online. 2009

23. ASTM International (2010) ASTM D4318: standard test methods for liquid limit, plastic limit, and plasticity index of soils. ASTM International, West Conshohocken

24. ASTM International (2011) ASTM D2487: standard practice for classification of soils for engineering purposes (unified soil classification system). ASTM International, West Conshohocken

25. Ulm FJ et al (2007) Statistical indentation techniques for hydrated nanocomposites: concrete, bone, and shale. J Am Ceram Soc 90(9):2677-2692

26. Lee $\mathrm{H}$ et al (2014) Preliminary study of lime-pozzolan based cement after exposed to high temperatures. Int'l J Adv Agric Environ Engg (IJAAEE) 1(1):6-12

\section{Publisher's Note}

Springer Nature remains neutral with regard to jurisdictional claims in published maps and institutional affiliations.

\section{Submit your manuscript to a SpringerOpen ${ }^{\circ}$ journal and benefit from:}

- Convenient online submission

- Rigorous peer review

- Open access: articles freely available online

- High visibility within the field

- Retaining the copyright to your article

Submit your next manuscript at $\boldsymbol{\nabla}$ springeropen.com 